\title{
BNCC e pandemia Covid-19: impactos causados em uma escola EJA cearense
}

\author{
CNCB and Covid-19 pandemic: impacts on youth and adults school of Ceará \\ BCCN y pandemia Covid-19: impactos en una escuela para jóvenes y adultos en Ceará
}

Recebido: 23/11/2021 | Revisado: 28/11/2021 | Aceito: 29/11/2021 | Publicado: 09/12/2021

\author{
Mario Jorge Nunes Costa \\ ORCID: https://orcid.org/0000-0002-7267-2434 \\ Universidade Federal do Ceará, Brasil \\ E-mail:costajorgemnunes@gmail.com \\ Antônio Jorge Lima Barbosa \\ ORCID: https://orcid.org/0000-0002-2248-1082 \\ Secretaria da Educação do Estado do Ceará, Brasil \\ E-mail:professorjorge2010@gmail.com \\ Wendel Melo Andrade \\ ORCID: https://orcid.org/0000-0001-8921-7326 \\ Secretaria da Educação do Estado do Ceará, Brasil \\ E-mail:professorwendelmelo@gmail.com \\ Francisco Arnaldo Lopes Bezerra \\ ORCID: https://orcid.org/0000-0002-3560-0730 \\ Universidade Federal do Ceará, Brasil \\ E-mail:arnaldobezerraph@gmail.com \\ Maria Jose Costa dos Santos \\ ORCID: https://orcid.org/0000-0001-9623-5549 \\ Universidade Federal do Ceará, Brasil \\ E-mail:mazzesantos@ufc.br
}

\begin{abstract}
Resumo
Este trabalho pretendeu analisar em que medida o Projeto Político Pedagógico (PPP), o regimento escolar e o currículo de uma escola pública cearense foram afetados por ambos: pandemia da Covid-19 e pelas novas orientações curriculares para a área de Matemática, advindas da BNCC. Para tanto, houve um estudo bibliográfico a respeito de temáticas como: PPP e regimento escolar e sua importância na administração escolar; o impacto da Covid-19 nas instituições escolares; as orientações e impactos da BNCC para a educação e ensino de Matemática associado a investigação do caso do Centro de Educação de Jovens e Adultos José Walter, valendo-se de uma análise documental do PPP e do regimento da escola, e das orientações pedagógicas da SEDUC-CE e do Conselho Estadual de Educação do Ceará, para fins de validar a BNCC e coordenar as ações escolares durante a pandemia. Os dados revelaram que ambos os eventos proporcionaram: o desenvolvimento de um currículo baseado em competências e habilidades; a integração de tecnologias ao currículo, por meio de um ensino de forma remota com possibilidades de se fazê-lo de forma hibrida.
\end{abstract}

Palavras-chave: BNCC; Covid-19; Ensino de Matemática; Gestão escolar.

\begin{abstract}
This work intended to analyze how the pedagogical politic project (PPP), school regiment and curriculum of public school in Ceará, Brazil, were affected by both Covid-19 and the guidelines of the new Common National Curriculum Bases (CNCB) to teaching of mathematics. Thereby, made up a bibliographic study about themes like: PPP and school regiment and their importance for school administration; the impact of Covid-19 in schools; CNCB guidelines and impacts for education and for teaching of mathematics associated with the case investigation of youth and adults education center Jose Walter by document analysis of: PPP, school regiment; pedagogical guidelines from Ceará secretary of education and State Council of Education of Ceará to deploy the CNCB and to coordinate school actions during the pandemic scenario. The data revealed that both events provided: the development of a curriculum based in skills and abilities; integration of technologies to the curriculum, by a remote teaching and the possibility of development of hybrid teaching.
\end{abstract}

Keywords: CNCB; Covid-19; Teaching of Mathematics; School management.

\section{Resumen}

Este trabajo analizó como el proyecto político pedagógico (PPP), regimiento escolar y el currículo de una escuela pública del Ceará, Brasil, fue afectado por ambos: pandemia Covid-19 y por las nuevas orientaciones curriculares para enseñar matemáticas, viniendo de las nuevas bases común curricular nacional (BCCN). En ese sentido, se hizo un estudio bibliográfico sobre temas como: PPP y regimiento escolar y su importancia en la administración escolar; el impacto de Covid-19 en las instituciones escolares; directrices y impactos del BCCN para la educación y la enseñanza de las matemáticas asociado a una investigación del caso del centro de educación para jóvenes y adultos Jose Walter, a 
través de una análisis de documentos del PPP, regimiento de la escuela, lineamientos pedagógicos del departamento de educación y de la junta estatal de educación del estado de Ceará, para implementar la BCCN y coordinar las acciones de la escuela durante la pandemia. Los datos revelaron que ambos proporcionaron: el desarrollo de un currículo por destrezas y habilidades; la integración de tecnologías al currículo, a través del aprendizaje remoto con posibilidades de hacerlo de forma híbrida.

Palabras clave: BCCN; Covid-19; Enseñanza de Matemáticas; Gestión escolar.

\section{Considerações Iniciais}

A Base Nacional Comum Curricular (BNCC), desde que a sua versão definitiva foi aprovada, em 2017, e teve implantação definida segundo a resolução $\mathrm{n}^{\circ}$ 2, de 22 de dezembro de 2017, do Conselho Nacional de Educação, que: "institui e orienta a implantação da Base Nacional Comum Curricular, a ser respeitada obrigatoriamente ao longo das etapas e respectivas modalidades no âmbito da Educação Básica." (Brasil, Conselho Nacional de Educação-Resolução no 2, de 22 de dezembro de 2017, p. 1), tem sido um sinal de contradição, sofrendo críticas por parte de docentes, gestores e técnicos em educação, muito por conta da ideia de uma BNCC que, traz de forma normativa, tendências que visam homogeneizar os currículos para o ensino (Lopes, 2018).

Como argumenta Lopes (2018), não somente pelo seu conteúdo, mas também pela forma que poderá ser interpretada e aplicada nas escolas, a BNCC não tem superado as limitações que tem atingido o desempenho escolar dos alunos. Embora haja críticas dos docentes e de autores que estudam o currículo, também há aqueles que defendem a BNCC como um avanço necessário e gradual ao sistema de ensino brasileiro, tais como o instituído Movimento pela Base Nacional Comum Curricular (MBNCC), o qual defende a ideia da necessidade de termos reunidos conteúdos mínimos para os currículos, não é apresentado como ponto controverso entre críticos e simpatizantes, o que se está a pontuar é como cita Bezerra (2020, p. 20):

...de que maneira estarão incluídas as vozes dos agentes sociais pertinentes ao campo escolar, professores, alunos, comunidade escolar? Qual voz será ouvida nesse complexo construto que é uma base nacional para o ensino em um país continental de multifronteiras geográficas, econômicas e sociais?

Outro ponto de consenso entre os educadores é com relação a sua implantação. Sabe-se que qualquer mudança que se faz no sistema de ensino demanda tempo e planejamento para efetivação, principalmente para reformulações a respeito do conteúdo e da maneira como o currículo escolar é trabalhado. Entretanto, a adesão e implantação das propostas da BNCC não se fazem de forma simples e imediata nas escolas, visto que o currículo constitui um campo de contínuos conflitos, requerendo uma ampla discussão, reflexão e negociação dos entes educativos para sua efetivação (Santos, 2018).

Em seus estudos, Santos (2018) problematiza sobre este documento e sua implantação nas escolas, nos fazendo refletir sobre questionamentos do tipo: afinal a escola conseguirá pôr em prática o que indica a BNCC? Quem de fato deve decidir o que os alunos devem aprender? E os subalternos falam? Semelhantes críticas à BNCC são também feitas por Young (2014), Macedo (2016) e Lopes (2015), ao entenderem que o citado documento não reflete a diversidade cultural e regional brasileiras, mas se traduz na homogeneização de um currículo centralizado e imposto por interesses de grupos particulares que exerceram seu poder em sua elaboração.

Devido aos conflitos no campo do currículo, quanto à educação matemática, mais especificamente no contexto da educação de jovens e adultos, observa-se a necessidade de um amplo processo de debates entre docentes, gestores e secretarias de educação, para que a implantação da nova BNCC seja exitosa e possa se alinhar ao planejamento de médio e longo prazo das ações e metas a serem cumpridas pelas escolas, sendo que a base sofreu críticas por parte dos educadores no sentido de que excluiu a modalidade da EJA no que diz respeito as orientações curriculares, tanto em suas versões preliminares, quanto na sua edição final (Dourado et al, 2021, Ferreira, 2019, Moraes et al., 2019). Para contornar este problema, algumas secretarias estaduais de educação, como no caso do estado do Ceará, optaram por desenvolver uma Matriz de Conhecimentos Básicos 
(MCB) (Matriz de Conhecimentos Básicos - SEDUC/CE, 2021), que se inspirou em algumas competências e habilidades contidas nas BNCC, visando contemplar algumas das necessidades formativas próprias da EJA.

No que trata da educação de jovens e adultos da rede pública estadual cearense, a Secretaria de Educação do Estado do Ceará (SEDUC-CE) elaborou e divulgou, a partir do ano de 2020, uma compilação da referida MCB a ser admitida nas escolas, sendo que sua implantação, ao longo dos anos de 2020 e 2021, está se fazendo sentir, de forma mais expressiva, por meio das alterações nos currículos das escolas, em que cada instituição elabora o seu Plano de Matriz Curricular (PMC), inspirado na MCB.

Entretanto, os anos de 2020 e 2021 também tem apresentado outro desafio para os sistemas de ensino, que é a pandemia do vírus Covid-19, que obrigou a adoção de medidas de restrição de circulação de pessoas por meio do lockdown, como medida sanitária para fins de conter a disseminação do respectivo vírus, o que impossibilitou as aulas presenciais nas escolas, e as obrigou a adotarem o ensino remoto e as vezes híbrido, para garantir o desenvolvimento das aulas e demais atividades administrativas-pedagógicas. Isto exigiu como prioridade máxima, as vezes até de modo repentino, aos docentes e discentes a adotarem meios tecnológicos digitais para fins educativos (Couto, Couto, Cruz, 2020, Garcia et al, 2020; Moreira et al, 2020), porém pode ter, ao mesmo tempo, limitado ou impossibilitado o desenvolvimento do planejamento educacional e das demais funções socioeducativas das escolas.

Como se vê, a adaptação ao contexto pandêmico por parte das escolas afetou profundamente a estrutura e organização das mesmas, alterando inclusive o conteúdo do seu Projeto Político Pedagógico (PPP) e do seu regimento, em que estes devem necessariamente ter uma característica flexível, a qual esteja aberta a contemplar as mudanças que o cenário socioeducativo sofre ao longo do tempo (Azevedo, Andrade, 2012). O PPP é entendido, ao mesmo tempo, como um balizador útil das ações e metas que a gestão deseja executar ao longo de seu mandato e um norteador para os caminhos futuros que a instituição de ensino poderá trilhar para melhor desenvolver suas funções educacionais, desde que esse projeto seja construído de forma colaborativa entre todos os membros que compõem a instituição (Jesus, 2015, Veiga, 2008).

$\mathrm{O}$ contexto de impactos gerados, simultaneamente, pela pandemia e pela implantação da base nacional suscitou a formulação de questionamentos: Quais as reformulações ocorridas na dinâmica de funcionamento e nos currículos escolares? Quais as adaptações que tiveram que ser efetuadas em suas estruturas físicas, humanas e organizacionais? Como as adaptações influenciarão a organização e o desenvolvimento das atividades futuras?

Assim, tentando achar respostas a estes questionamentos, o objetivo deste artigo é investigar como o advento da BNCC, por meio da adoção e implantação da MCB referente a matemática e suas tecnologias, bem como as adaptações arquitetadas pela SEDUC-CE, para garantir o acesso à educação no contexto da pandemia do Covid 19, impactaram a organização e desenvolvimento das atividades pedagógicas de uma escola de educação de jovens e adultos da rede pública estadual cearense, tomando o caso especifico do ensino de matemática da mesma.

Para cumprir com seu objetivo, este artigo desenvolveu uma pesquisa por meio de duas vias: 1- um estudo bibliográfico, contemplando as seguintes temáticas: a importância do PPP e do regimento na gestão escolar; os impactos da pandemia Covid-19 nas escolas brasileiras; o currículo de conhecimentos matemáticos propostos pela BNCC; 2- pesquisa de campo em uma escola de educação de jovens e adultos da rede pública estadual, através da metodologia de um estudo documental, com a coleta e análise do seguintes documentos: PMC de Matemática relativo ao $3^{\mathrm{O}}$ ano, PPP, regimentos escolares; resolução do Conselho Estadual de Educação do Ceará (CEE-CE); guia de orientação, diretrizes e MCB elaborados pela SEDUC-CE para, respectivamente, orientar as atividades educacionais durante o contexto da pandemia Covid 19 e para implantar a BNCC nas escolas da rede estadual de ensino. 


\section{BNCC, Educação Matemática e Pandemia Covid-19: influências nas alterações dos currículos, dos PPPs e dos Regimentos Escolares}

Segundo Veiga (2008), a ação de projetar significa lançar para frente, revelando intenções de fazer e realizar, porém o desenvolvimento do PPP escolar é algo dinâmico, não se limitando a simples elaboração de um documento a ser encaminhado e arquivado, mas é construído e vivenciado em todos os momentos por todos os envolvidos no processo educativo escolar, configurando-se como um dos mecanismos de participação efetiva, de acordo com Ribeiro (2021). Segundo Jesus (2015) o PPP, após a LDB 9394/96, reconfigura-se como um planejamento estratégico das ações administrativas e pedagógicas a serem desenvolvidas na escola, de modo que se promova mais eficiência no trabalho escolar.

Outro documento de grande importância para as escolas é o regimento escolar, o qual consiste em um conjunto de normas que preside a sua organização e seu funcionamento (Watanabe, 2000). Num viés democrático, Ribeiro (2021) argumenta que este documento pode se tornar uma via de acesso à educação de qualidade, desde que a comunidade escolar se conscientize por meio do mesmo de seus direitos e deveres ao atuarem de forma ativa na vida da escola, culminando na formação de cidadãos críticos e participativos na sociedade em que estão inseridos.

Reflexos deste dinamismo e da condição estratégica do PPP e do regimento escolar se fizeram refletir no contexto da pandemia Covid 19, a qual se tornou global em março de 2020, obrigando as pessoas a entrarem em isolamento social, interrompendo assim o andamento de diversas atividades que se realizavam de forma presencial, como foi o caso das aulas síncronas, que tiverem que se adaptar ao modo remoto muitas vezes de modo improvisado e sem uma infraestrutura adequada (Couto, Couto, Cruz, 2020). Para tanto, as instituições de ensino e os indivíduos se valeram dos recursos da cibercultura, como as redes de internet de alta velocidade e os computadores pessoais, laptops, tablets e smartphones, de modo a viabilizar uma infinidade de atividades de ensino e administração escolar e acadêmica, tais como: transmissões de aulas ao vivo, cursos online, ambientes virtuais de aprendizagem, laboratórios virtuais, reuniões pedagógicas e de colegiado, provas e trabalhos online, debates etc. (Couto, Couto, Cruz, 2020, Garcia et al, 2020, Moreira et al, 2020).

Apesar do contexto da cibercultura apresentar perspectivas promissoras para a educação, a migração das atividades de ensino do modo presencial para o remoto/hibrido também revelaram problemas e dificuldades, dentre eles destacam-se: as desigualdades sociais dos estudantes brasileiros, sendo que aqueles que apresentam baixa renda ou tem acesso limitado aos meios midiáticos e as redes de internet de alta velocidade, ou não tem nenhum acesso as redes de internet, inviabilizando sua participação em atividades remotas; a precariedade das unidades escolares e até de secretarias de educação em dispor de redes de internet de alta velocidade e/ou possuírem dispositivos para fazer transmissões via web; o desconhecimento ou falta de habilidade de muitos educadores e estudantes em utilizar recursos tecnológicos digitais para fins educativos; a falta de um planejamento de médio e longo prazo de governos e de instituições de ensino público ou privadas para implementação e desenvolvimento de atividades de ensino remotas/hibridas (Couto, Couto, Cruz, 2020, Garcia et al, 2020, Zucoloto, 2021). Além destas dificuldades descritas, Zucoloto (2021) argumenta que o desenvolvimento de atividades pedagógicas de forma hibrida constitui um desafio, o qual requer a integração de espaços, tempos e metodologias para oferecer as melhores experiencias de aprendizagem individuais.

Todo o cenário anteriormente descrito de avanços e dificuldades gerados pelo ensino remoto em virtude da pandemia, em termos organizacionais, exigiu das instituições de ensino e governos análise, discussões, soluções e planejamento de modo a atender as demandas requeridas, o que possivelmente inspirou a depuração e reformulação dos PPPs e dos regimentos escolares. No caso específico do Conselho de Educação do Estado do Ceará (CEE-CE), e da Secretaria de Educação Básica do Estado do Ceará (SEDUC-CE), foram lançadas, respectivamente: uma resolução, um guia de orientação e diretrizes nesse período que impactaram o planejamento e dinâmica das escolas, sendo que uma análise das mesmas e suas implicações nas possíveis reformulações do regimento e do PPP de uma escola da rede estadual de ensino serão analisadas e discutidas em 
seções posteriores deste trabalho.

O contexto pandêmico de 2020, continuado em 2021, inspirou também reformas curriculares ao longo do Brasil. Para entender o contexto e o impactos dessas reformas, faz-se necessário compreender o que é currículo, e como ele é construído e negociado entre os pares.

Em sua origem etimológica, Santos (2018) argumenta que a palavra currículo significa rota ou direção a ser seguida por individuo ou grupo de indivíduos. Com base nessa definição, num sentido literal, o currículo escolar configura-se como algo normativo, que é simplesmente apresentado e implementado nas escolas, sem que haja qualquer negociação entre as partes do que deve ou não ser contemplado. Contudo, alguns teóricos afirmam que o currículo se configura como um campo de significados e de poder, não se traduzindo numa mera reprodução de documentos oficiais, mas num intenso campo de debates e batalhas de caráter ideológico e cultural, cabendo assim uma intensa troca entre os indivíduos e intercâmbios entre os elaboradores das políticas educacionais, e os executores das mesmas (Passos, Nacarato, 2018, Santos, 2018).

Entender o currículo como uma instância de conhecimento e poder, manifestadas pelas escolhas, intencionalidades e ideologias nele presente, de forma explicita ou oculta, nos faz perceber que o seu teor revela intenções e propósitos definidos em prol dos interesses das classes hegemônicas (Lopes, 2015, Apple, 2002, Arroyo, 2011).

No cotidiano escolar, observa-se este fenômeno na seleção e organização dos conteúdos, nas metodologias e práticas pedagógicas, principalmente aquelas que guardam um caráter reprodutivista, nas relações e interrelações entre os sujeitos no espaço educativo, entre outras circunstâncias. Tudo isso faz do currículo um território de disputas e embates travados entre grupos dominantes e dominados. Desse modo, o currículo não pode ser interpretado no seu sentido puramente técnico, ele deve ser compreendido no contexto econômico, político e social.

Um reflexo destes conflitos do currículo se faz sentir na gênese e implantação da BNCC, principalmente no que se refere ao campo da matemática, visto que os educadores desta área não são favoráveis a proposta defendida pela base, a qual está centrada em competências e habilidades, bem como possivelmente não contempla as necessidades dos professores das séries iniciais, uma vez que estes em sua maioria são pedagogos, os quais apresentam lacunas em sua formação em matemática que os deixam inseguros para lecionar tal disciplina, conforme sustentam Passos e Nacarato (2018). Estes autores entendem que a elaboração da versão final da BNCC representou uma submissão dos docentes e gestores das escolas de ensino básico a interesses de instituições privadas e de outros organismos que não necessariamente estão diretamente ligados à educação, como o caso do Fundação Lemann e o Google.org, uma vez que os educadores não puderam participar efetivamente da elaboração do texto final que fora aprovado.

Os conflitos associados ao currículo traduzem o mesmo como algo não fechado, mas interpretável e negociável, principalmente levando em consideração as próprias características da BNCC em sua integra, uma vez que Santos (2018) afirma que a mesma contempla a organização dos conteúdos escolares em unidades temáticas (no caso da matemática, as unidades são: número, álgebra, geometria, grandezas e medidas, probabilidade e estatística), sendo que cada unidade temática abrange um leque de objetos de conhecimento, associadas a formulação de habilidades, os quais podem ser abordados de diversas formas, dependendo da maneira como a política pública será entendida e o qual o plano de metas que será traçado pelas diferentes secretarias de educação e organizações de ensino privado para se adaptar as BNCC.

Por outro lado, em virtude da proposta aberta que a BNCC representa, alguns autores como Costa, Sousa e Cordeiro (2020) entendem o advento desta como uma mudança paradigmática progressista para a educação matemática, com um currículo de conhecimentos interligados, sendo que a disciplina deixa de ser trabalhada sem tantas fórmulas e memorizações como tradicionalmente tem sido ministrada, para enfatizar a reflexão e a interpretação, bem como instigar o aluno a ter uma postura mais ativa, ao transformar o processo de aprendizagem dos mesmos como uma ação de pesquisa e também a cidadania dos mesmos ao saberem tomar decisões. Devido ao processo de mudança representado pela BNCC, seu processo de 
implantação nas escolas requer mudanças e adaptações em sua dinâmica e funcionamento, incluindo principalmente o currículo escolar e possivelmente o PPP.

Assim, baseado nas discussões tecidas entre efeitos da pandemia Covid-19 na educação, BNCC e ensino de matemática, currículo, PPP e regimento escolar, este artigo irá, nas sessões posteriores, analisar as interrelações entre estes temas no contexto de ajustes ocorridos no currículo de matemática, no projeto político pedagógico e no regimento de uma escola de educação de jovens e adultos da rede pública estadual cearense, ao vivenciar simultaneamente o lockdown e o seus efeitos para a educação, bem como a implantação da base nacional.

\section{Contexto e Metodologia}

O principal lócus de onde se extraiu os dados que compõem esta pesquisa se trata do Centro de Educação de Jovens e Adultos (CEJA) José Walter, o qual está localizado no bairro de mesmo nome na periferia de Fortaleza, e que é parte integrante da rede pública estadual cearense.

Tradicionalmente, desde sua fundação até meados de fevereiro do ano de 2020, a escola contava com um regime semipresencial de ensino, em que alunos estudavam individualmente as disciplinas de forma modular, contando com as dependências da escola para fins de: estudo; consulta de livros na biblioteca; acesso a laboratório de informática para pesquisas; alimentação escolar; consulta aos professores para tirar dúvidas; aplicação de provas e demais atividades escolares. Em 2021, a escola contou com um efetivo de quase 3.000 discentes nas modalidades presencial, em 9 Centros Socioeducativos em Fortaleza, e semipresencial, no próprio CEJA José Walter.

A pesquisa de que trata este artigo tem perfil qualitativo, segundo a definição de Bogdan e Biklen (1994) e de caráter descritivo, de acordo com Gil (2008), pois tende a descrever e analisar o fenômeno em estudo de forma a compreender como ele surgiu, valorizando o processo e não simplesmente os resultados. A técnica de investigação utilizada na pesquisa foi a análise documental, de acordo com Corsetti (2006), visto que os dados de campo coletados para compor este artigo consistem em documentos como: Plano de Matriz Curricular (PMC) de Matemática, relativo ao $3^{\circ}$ ano, PPP (ano de 2021) e Regimentos Escolares (anos de 2016 e 2021) do CEJA José Walter ; Matriz de Conhecimentos Básicos (MCB), Guia de Orientações sobre o Ensino remoto/híbrido e Diretrizes Operacionais para Organização do Trabalho Escolar durante o Segundo Semestre e das Atividades letivas no ano de 2020, todos estes elaborados pela SEDUC-CE; resolução 481 de 27 de Março de 2020, do Conselho Estadual de Educação (CEE-CE).

A escolha pela técnica definida por Corsetti (2006), se deu pelo fato de que a autora adota uma abordagem de não apenas ler e descrever o conteúdo dos documentos, mas de ser capaz de questioná-los e criticá-los à luz da problemática da pesquisa, do contexto e da literatura coletada para estudar o fenômeno investigado relacionado aos referidos documentos.

Na próxima seção apresenta-se e analisa-se trechos dos referidos documentos baseado na metodologia de Corsetti (2006).

\section{Análise da Matriz de Conhecimentos Básicos, das diretrizes operacionais da SEDUC-CE e da resolução do CEE-CE a respeito da pandemia Covid-19, e suas interrelações com a elaboração do PPP e atualização do regimento de uma escola da rede pública estadual cearense}

Conforme o que foi argumentado o CEJA José Walter, até meados de fevereiro de 2020, operava de modo semipresencial em três turnos. Este modo de operação estava descrito e organizado no regimento escolar do quadriênio da gestão, referente aos anos 2013-2016, sendo uma continuidade de regimentos elaborados em gestões anteriores, pois pouco havia alterações no modo da organização escolar até então, segundo se apresenta um recorte do artigo 74 do mesmo a seguir: 
“O CEJA José Walter possui regime semipresencial modular, respeitando a base nacional comum do currículo...” (Centro de Educação de Jovens e Adultos José Walter-Regimento Escolar, 2016, p. 19).

Entretanto, em meados de fevereiro de 2020, a Pandemia Covid 19 espalhou-se pelo Brasil, exigindo medidas de restrição de circulação de pessoas, tal como lockdown. Este novo cenário mobilizou mudanças em todas as esferas sociais, o que exigiu a reformulação de práticas como a do ensino, o qual passou a entrar num regime especial de atividades escolares não presenciais, conforme o que determinou o artigo $1^{\circ}$ e seu parágrafo único, da resolução no 481 de 27 de março de 2020 , do Conselho Estadual de Educação do Ceará (CEE-CE) (Conselho Estadual de Educação do Ceará, 2020):

Art. $1^{\circ}$ Dar orientações sobre o estabelecimento de regime especial de atividades escolares não presenciais para fins de cumprimento do calendário letivo do ano de 2020.

Parágrafo único - Entenda-se, nesse contexto, por atividades escolares não presenciais aquelas realizadas sem a presença de alunos e professores nas dependências escolares, no âmbito das instituições ou redes de ensino públicas e privadas da educação básica e ensino superior, pertencentes ao Sistema de Ensino do Estado do Ceará (Conselho Estadual de Educação do Ceará,2020, p. 3).

As atividades não presenciais, destacadas na citada resolução do CEE-CE, configuraram-se como uma medida emergencial para viabilizar as atividades de ensino escolares de forma remota, contudo, o documento não faz qualquer menção do que sejam tais atividades, nem de que forma elas serão desenvolvidas para cumprir o intuito desejado, sendo um indício de improvisação do ensino para atender as necessidades do contexto pandêmico, conforme destacam Couto, Couto e Cruz (2020).

A respectiva resolução implicou na reformulação do sistema educacional do Ceará, com a adoção do ensino remoto nas escolas cearenses, por meio do Plano de Atividades Domiciliares. Este plano foi adotado no primeiro semestre de 2020, e sofreu uma atualização no segundo semestre daquele ano, através das Diretrizes Operacionais para a Organização do Trabalho Escola Durante o Segundo Semestre e das Atividades Letivas no Ano de 2020 (Secretaria da Educação do Estado do CearáDiretrizes Operacionais para a Organização do Trabalho Escola Durante o Segundo Semestre e das Atividades Letivas no Ano de 2020), em que se continuou o ensino remoto, e se cogitou a possibilidade do ensino híbrido:

Todas as escolas iniciarão o semestre exclusivamente com o ensino remoto. A primeira tarefa da escola, portanto, ao planejar o segundo semestre, por meio do núcleo gestor e suas/seus professoras/es, é a qualificação do ensino remoto. $\mathrm{Na}$ possibilidade de as atividades presenciais serem autorizadas por ato do Governador do estado do Ceará, ao longo do semestre, haverá a necessidade de se discutir e estruturar o ensino híbrido, aqui entendido como a coexistência do ensino presencial e remoto (Secretaria da Educação do Estado do Ceará- Diretrizes Operacionais para a Organização do Trabalho Escola Durante o Segundo Semestre e das Atividades Letivas, 2020, p.2).

As citadas diretrizes operacionais revelam que a educação cearense era predominantemente presencial, e que necessitou se adaptar de forma urgente ao contexto remoto. Para tanto, as diretrizes informam a necessidade de que os gestores e docentes qualifiquem as escolas para esse fim, porém não há qualquer menção de como isso será feito, nem sobre o possível desenvolvimento de capacitações de gestores e docentes de formá-los para a realidade remota, corroborando com o provável cenário de dificuldades que as escolas enfrentariam nesse contexto (Couto, Couto, Cruz, 2020, Garcia et al, 2020, Zucoloto, 2021).

Neste contexto, é importante enfatizar o desafio vivenciado pelos docentes que, de uma hora para outra, tiveram que adotar novas metodologias e tecnologias, e começaram a ensinar e aprender de outras formas, uma vez que estavam acostumados à sala de aula presencial, em que ministravam aulas com pouco ou quase nenhum auxílio de TIC, sendo que os professores tiveram que se reinventar, pois a grande maioria não estava preparada e nem formada para isso (Couto, Couto, Cruz, 2020, Garcia et al, 2020, Zucoloto, 2021).

De forma complementar e ampliando as diretrizes supracitadas a SEDUC/CE, no contexto do segundo semestre do 
ano de 2021 com o novo cenário da pandemia marcado pelo avanço da vacinação no Brasil contra o Covid-19, o qual se caracterizou pela diminuição gradual do número de infecções e mortes causadas pelo respectivo vírus, lançou o guia de orientações sobre o ensino remoto/híbrido, que se traduziu no melhor detalhamento das atividades pedagógicas, principalmente aquelas que poderão ser efetuadas de forma presencial. O trecho destacado do citado documento enfatiza a possibilidade do desenvolvimento de atividades de ensino de forma hibrida:

Diferentemente de definições mais convencionais, nas quais o ensino híbrido se dá apenas com a combinação de presencial e online, para a Seduc-CE, no ensino remoto pode e deve haver ensino híbrido, a fim de garantir um atendimento mais equitativo às/aos estudantes, combinando tecnologias, espaços, tempos e pedagogias (Secretaria da Educação do Estado do Ceará -Guia de Orientações sobre o Ensino Remoto/Híbrido, 2021, p10).

Ambas diretrizes e guia de orientação inspiraram e estimularam a reformulação do PPP em 2021 do CEJA José Walter, em que se contemplou uma reorientação de seu modo de funcionamento, passando do sistema semipresencial de ensino para o remoto/híbrido, porém contando com algumas atividades de forma presencial, como ilustra a figura 1 a seguir, consistindo de um recorte da página 34 do novo PPP para o ano de 2021:

Figura 1 - Recorte da página 34 do PPP do CEJA José Walter, em que se destaca a metodologia de trabalho da escola, contando com momentos virtuais e presenciais de atendimento.

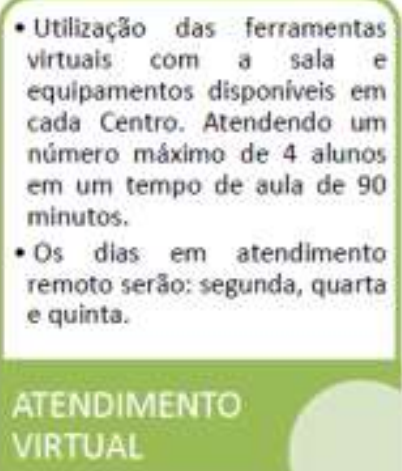

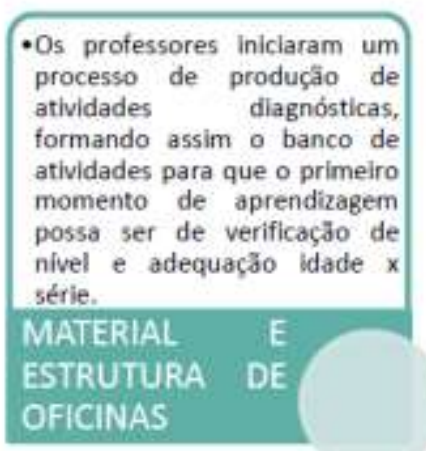

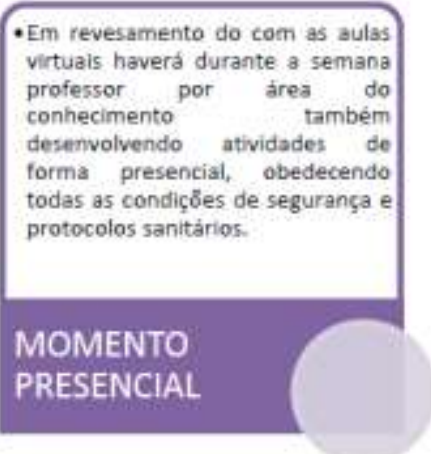

Fonte: PPP CEJA José Walter- edição (2021).

Observa-se no PPP do CEJA que a escola adotou algumas ferramentas virtuais, porém sem especificá-las. Também é possível se destacar, do citado documento, que a escola adotou o sistema híbrido, ao mencionar que irá revezar as atividades remotas com momentos presenciais, entretanto não há detalhes de como tal modalidade de ensino poderá ser desenvolvida de forma pedagógica, configurando-se o ensino híbrido como um desafio ainda a ser refletido e enfrentado pelos gestores e corpo docente da escola, assemelhando-se ao que foi defendido por Zucoloto (2021).

Contudo, apesar da atualização do PPP em 2021, o qual trata do ensino remoto e denota a possibilidade do ensino híbrido no CEJA, não se observa citação destas modalidades de ensino no novo regimento escolar aprovado em 2021 (Centro de Educação de Jovens e Adultos José Walter -Regimento Escolar, 2021), permanecendo o que tradicionalmente é praticado na escola, que é o sistema semipresencial. Isto pode configurar indícios de falta de formação ou discussão e análise mais embasada dos gestores e docentes da escola a respeito das modalidades remota/hibrida, ou pode indicar que a adoção delas será apenas em caráter temporário, enquanto o cenário pandêmico não se encerra (Couto, Couto, Cruz, 2020, Garcia et al, 2020, Zucoloto, 2021).

Outra medida implementada a partir de julho de 2021 no CEJA, de acordo com o que foi relatado, foi a atualização e 
divulgação, por parte da SEDUC-CE, da Matriz de Conhecimentos Básicos (MCB) (Secretaria da Educação do Estado do Ceará-Matriz de Conhecimentos Básicos, 2021), a qual se inspira nos pressupostos curriculares da BNCC. A SEDUC-CE também informou que a MCB atuou como uma solução no contexto pandêmico, em que foi necessário reinventar e adaptar os processos de ensino no sentido de garantir o direito à educação, segundo o que se destaca no primeiro parágrafo desse documento, na página 5:

Diante dos muitos desafios trazidos pela pandemia de Covid-19, a educação passa por grandes transformações que modificaram a forma de nos comunicarmos, as relações que se desenvolvem entre os sujeitos da comunidade escolar e, de forma especial, os processos de ensino e de aprendizagem. A necessidade premente da construção de novos caminhos para a garantia do direito à educação tem levado educadores do mundo inteiro a reinventar práticas pedagógicas e a utilizar recursos didáticos e metodológicos que antes não pertenciam ao repertório da grande maioria dos professores e gestores escolares (Matriz de Conhecimentos Básicos-SEDUC/CE, 2021, p 5).

No que trata da área de matemática, a MCB esclarece que busca organizar os objetos de conhecimento por série, visando desenvolver os conteúdos de forma lógica e progressiva, sendo que a estrutura interna de cada objeto é detalhada em objetivos específicos, de forma que haja uma flexibilidade de aplicação da MCB. Para adequar o currículo de matemática do CEJA a referida proposta, solicitou-se aos professores de matemática da escola que formulassem o Plano de Matriz Curricular (PMC), de modo a contemplar as diretrizes do documento da SEDUC, sendo que uma reprodução do respectivo plano para o terceiro ano do ensino médio está ilustrado na Figura 2:

Figura 2 - Reprodução do Plano de Matriz Curricular de Matemática, relativo ao $3^{\circ}$ Ano ou Etapa 3, página 1.

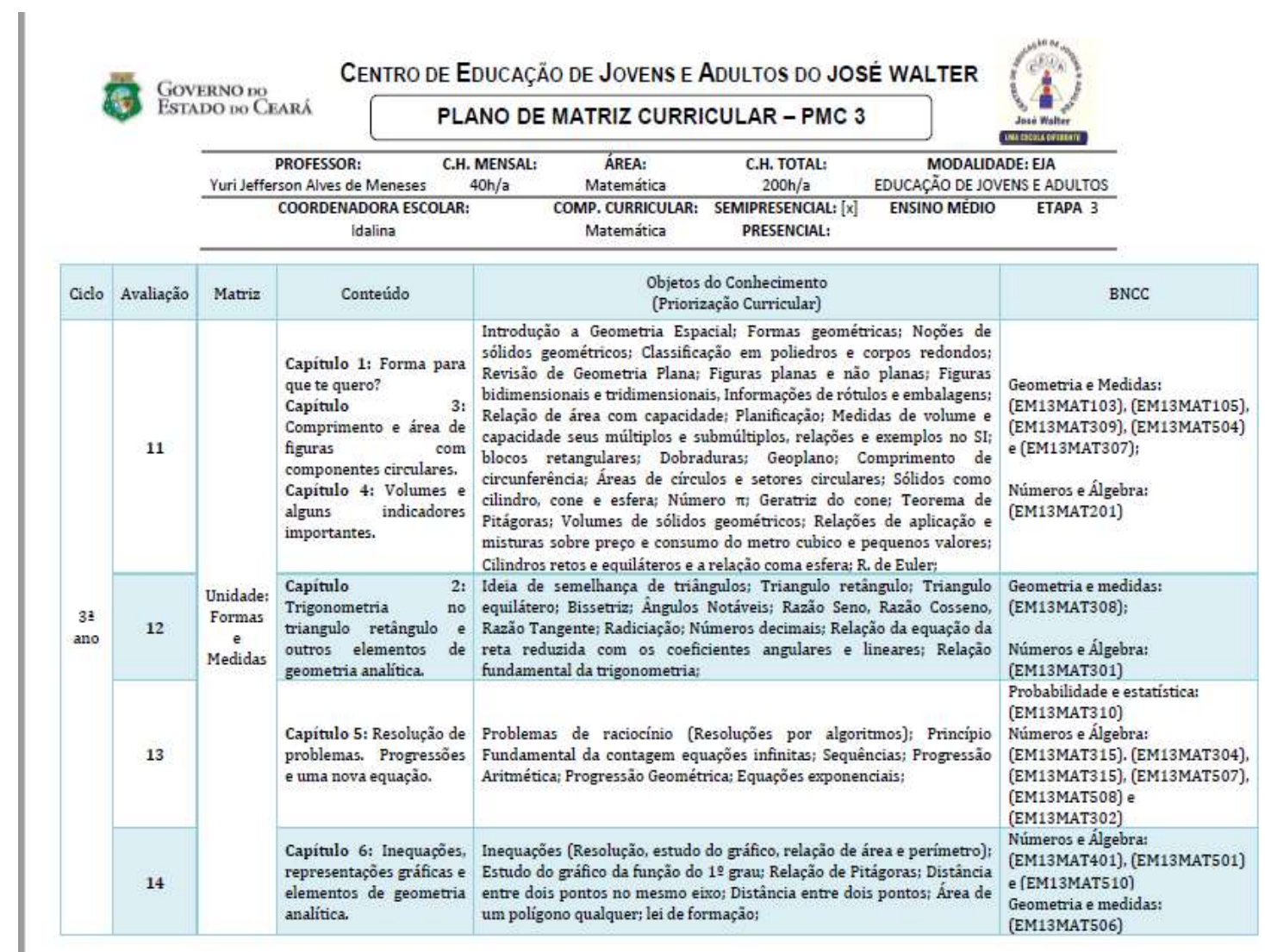

Fonte: Plano de Matriz Curricular de Matemática, $3^{\circ}$ Ano- CEJA JOSE WALTER (2021). 


\section{Considerações Finais}

Refletindo e buscando respostas para as perguntas que foram lançadas no início deste artigo, com base no que foi coletado e analisado, entendeu-se que :no que trata da educação matemática, a implantação da BNCC nas escolas representa uma mudança paradigmática na organização e no desenvolvimento curricular, ao se substituir um ensino tradicionalmente baseado em conteúdos, por outro que enfatiza o desenvolvimento de competências e habilidades. O caso do CEJA José Walter ilustra esta mudança, por meio da adoção e adaptação do currículo de matemática da escola à Matriz de Conhecimentos Básicos (MCB), abrindo perspectivas para mudanças também nas práticas pedagógicas e na forma como as avaliações serão desenvolvidas.

No que trata do contexto pandêmico, o impacto mais significativo para as escolas está no desenvolvimento das aulas, as quais adotaram temporariamente o sistema remoto, e estão se adaptando ao hibrido, mesclando aulas presenciais com atividades à distância, conforme o que destacaram o PPP do CEJA e também as diretrizes da SEDUC-CE. Para tanto, educandos e educadores devem se abrir para o uso de metodologias de aprendizagem ativas, e para desenvolver habilidades de uso pedagógico das TIC, de modo que auxiliem o desenvolvimento do processo educacional. Tal realidade irá, futuramente, exigir investimentos nas escolas em infraestrutura, recursos e formação, de modo a atender as demandas.

Para finalizar, registra-se a necessidade de se realizar estudos mais profundos a respeitos destes impactos gerados pelas duas mudanças que foram analisadas ao longo do texto, sendo assim alvo de interesse para outras pesquisas mais avançadas.

\section{Referências}

Apple, M. (2002). Educação e poder: educação e realidade. (14a ed.), Artmed.

Arroyo, M. G. (2011). Currículo, território em disputa. (2a ed.), Vozes.

Azevedo, M. A. R. de. \& Andrade, M. de F. R. de. (2012). Projeto Político-Pedagógico e o papel da equipe gestora: dilemas e possibilidades. Revista Interações, 8 (21), 204-218. https://revistas.rcaap.pt/interaccoes/article/view/1531.

Bezerra, F. A. L. (2020). O Encontro Nacional de Educação Matemática-ENEM: como espaço formativo dos professores que lecionam matemática nos anos iniciais do ensino fundamental. (Dissertação de Mestrado, Universidade Federal do Ceará, Fortaleza, CE). https://www.repositoriobib.ufc.br/000061/00006108.pdf.

Brasil. Conselho Nacional de Educação. Conselho Pleno. Resolução CNE/CP $n^{o} 2$, de 22 de dezembro de 2017. http://portal.mec.gov.br/index.php?option=com_docman\&view=download\&alias=79631 -rcp002-17-pdf\&category_slug=dezembro-2017-pdf\&Itemid=30192.

Bogdan, R. C.\& Biklen, S. K. (1994). Investigação qualitativa em educação: uma introdução à teoria e aos métodos. Porto Editora.

Centro de Educação de Jovens e Adultos José Walter (2021). Plano de Matriz Curricular de Matemática, $3^{\circ}$ Ano- CEJA JOSE WALTER, 2021. https://drive.google.com/file/d/1pfhim7cyF3cAtFac-ghTeqiAuCPyb5UO/view.

Centro de Educação de Jovens e Adultos José Walter (2021). Projeto Político Pedagógico-edição 2021. https://drive.google.com/file/d/17zBEcPiT1QUZu2guUJnkzb2PxbX5ZfI/view.

Centro de Educação de Jovens e Adultos José Walter (2021). Regimento Escolar-edição 2016. https://drive.google.com/file/d/11TYqjQQuMSaQ5mdObueEgl0lbuxb-z8/view.

Centro de Educação de Jovens e Adultos José Walter (2021). Regimento Escolar-edição 2021. https://drive.google.com/file/d/1wdWDvQtqTGWSU2eSF2nKL_4PIHri17BH/view.

Conselho Estadual de Educação do Ceará (2021). Resolução CEE $n^{\circ} \quad 481$, $27 \quad$ de março de 2020. https://www.consed.org.br/storage/download/5e8747a4dc9c6.pdf.

Corsetti, B. (2006). A análise documental no contexto da metodologia qualitativa: uma abordagem a partir da experiencia de pesquisa do programa de pósgraduaçao em educação da Unisinos. Unirevista, 1 (1), 32-46. https://d1wqtxts1xzle7.cloudfront.net/32358119/ART_05_BCorsetti-with-cover-pagev2.pdf?Expires $=1637886914 \&$ Signature $=V 316 j F H N m j U e 5 i s w H o G a u c Z R 1 K-a 2 w D c 43 t D k x 0 \sim G c z 8 O g O u B f J x g g o X 2 U K j J v H b q a 3 L 20 m k X J i 8 w V ~ R Y 7 J Q k B$ IRCzboBVTDUb22I7Wfe7QvB2X2f4FDvVXxAzB2R0NVc6g7s7rKzJjJ-fPhMu9M47dmEvJlvY5v9cweRPGRv8NiE8L1AzgJaOWoocKBD hKPwoHnu P7 RHaio7OiUjIFGjoRm fn1PE2m1vsWU7CK1L1Ov7HuxJTdTiyeL-zWg5cSGfdKLdVV0kNUNBdzIxi9MuPV1LUQnYqLJaj3ga7kKpQ6IPpDdqhJoczL5F10 ja n51eQvbKxaC12KdMF26s2SZCw_\&Key-Pair-Id=APKAJLOHF5GGSLRBV4ZA.

Costa, R. P. da, Sousa, C. \& Cordeiro, L. Z. (2020). O ensino de Matemática na Base Nacional Comum Curricular nos anos finais do Ensino Fundamental. Ensino Em Re-Vista, 27 (2), 572-594. https://www.periodicosdeminas.ufmg.br/periodicos/ensino-em-re-vista/. 
Couto, E. S., Couto, E. S. \& Cruz, I. de M. P. (2020). \#FIQUEEMCASA: Educação na Pandemia Covid 19. Interfaces Educativas 8 (3), $200-217$. https://periodicos.set.edu.br/educacao/article/view/8777/3998.

Dourado, D. L. O., Rocha, A. K. L. T., Morais, C. B. de O. \& Sudré, M. de F. S. A (2021). Direito à educação: a invisibilidade da EJA na BNCC. Revista de Políticas Públicas e Gestão Educacional - UESB (Itapetinga), 2(1),203-220. https://periodicos2.uesb.br/index.php/poliges/article/view/8489/5768.

Ferreira, L. C. (2019). A educação de jovens e adultos em tempos (im)prováveis e de (in)certezas: a bncc em discussão. Revista Augustus, 24 (47), 9-27. https://revistas.unisuam.edu.br/index.php/revistaaugustus/article/view/334/150 .

Garcia, J. A. D., Carvalho, M. das G. de S., Lima, S. J. F. de., Alves, L. R. de C., Silva, A. G. S. \& Oliveira, F. S. (2020). Ensino profissional e tecnológico na pandemia COVID-19: contexto político e educacional. Research, Society and Development, 9, (12), 1- 15. https://rsdjournal.org/index.php/rsd/article/view/10789/9769.

Gil, A, C. (2008). Como elaborar projetos de pesquisa. (6a ed.), Atlas.

Jesus, O. F. de (2015). Do projeto político pedagógico-PPP ao planejamento estratégico escolar-PEE. Revista de Gestão e Avaliação Educacional, 4 (8), 7-16. https://periodicos.ufsm.br/regae/article/view/17081/pdf.

Lopes, A. C. (2015). Por um currículo sem fundamentos. Revista Linhas Críticas (Brasília) $21 \quad$ (45), $445-466$. https://periodicos.unb.br/index.php/linhascriticas/article/view/4581/4179.

Lopes, A. C. (2018). Apostando na produção contextual do currículo. In: Aguiar, M. A. da S. \& Dourado, L. F. (Orgs.) A BNCC na contramão do PNE 20142024: avaliação e perspectivas. Recife: ANPAE [Livro Eletrônico], 23-27.

Macedo, E. (2016). Base nacional curricular comum: a falsa oposição entre conhecimento para fazer algo e conhecimento em si. Educação em Revista (Belo Horizonte), 32 (2), 45-68. https://www.scielo.br/j/edur/a/vDGdwyYrj9qbkcgk39vxcyF/?format=pdf\&lang=pt.

Moraes, M. S., Cunha, S. dos S. da., Voigt, J. M. R. (2019). Onde está a Educação de Jovens e Adultos na BNCC? In: Anais do V Colóquio Luso-Brasileiro de Educação, Universidade do Estado de Santa Catarina, Joinville.

Moreira, M. E. S., Cruz, I. L. da S., Sales, M. E. N., Moreira, N. I. T. \& Freire, H. de C. (2020). Metodologias e tecnologias para educação em tempos de pandemia COVID-19. Brazilian. Journal of Health Review, 3 (3), 6281-6290. https://www.brazilianjournals.com/index.php/BJHR/article/view/11584/9668 .

Passos, C. L. B.\& Nacarato, A. M. (2018). Trajetória e perspectivas para o ensino de Matemática nos anos iniciais. Estudos Avançados, 32(94), 119-135. https://www.scielo.br/j/ea/a/VqMq5VmXSk45CKXtvFmZZrN/?format=pdf\&lang=pt.

Ribeiro, F. da C. (2021). Gestão democrática e regimento escolar: uma conexão necessária. Revista Ibero-Americana de Humanidades, Ciências e Educação, 7.(7), 1169-1187. https://periodicorease.pro.br/rease/article/view/1765/737.cesso .

Santos, M. J. C. dos. (2018). O currículo de matemática dos anos iniciais do ensino fundamental na base nacional comum curricular (BNCC): os subalternos falam? Horizontes, 36 (1), 132-143. https://revistahorizontes.usf.edu.br/horizontes/article/view/571/265.

Secretaria da Educação do Estado do Ceará (2020). Diretrizes operacionais para organização do trabalho escolar durante o segundo semestre e das atividades letivas no ano de 2020. https://www.ceara.gov.br/wp-content/uploads/2020/08/diretrizes_continuidade_ensino_remoto.pdf.

Secretaria da Educação do Estado do Ceará (2021). Guia de orientações sobre o ensino remoto/hibrido na rede pública estadual de ensino do Ceará.https://www.ced.seduc.ce.gov.br/wp-content/uploads/sites/82/2021/08/GUIA-DE-ORIENTACOES-SOBRE-O-ENSINO-REMOTO_HIBRIDO2021V10link.pdf.

Secretaria da Educação do Estado do Ceará (2021). Martriz de Conhecimentos Básicos - MCB 2021. https://www.seduc.ce.gov.br/wpcontent/uploads/sites/37/2021/07/MCB-2021-Versao-0208_2021.pdf.

Veiga, I. P. A. (2008). Projeto político pedagógico da escola: uma construção coletiva. In: Veiga, I. P. A (Org.). Projeto Político Pedagógico da escola: uma construção possível. (24a ed.), Papirus editora, 11-35.

Watanabe, T. (2000). Papel do regimento escolar na organização e funcionamento da escola pública. Nuances, 6 (6),208-209. https://revista.fct.unesp.br/index.php/Nuances/article/view/142/200.

Young, M. (2014). Teoria do Currículo: o que é e por que é importante. Cadernos de pesquisa, 44(151), 190-202. https://www.scielo.br/j/cp/a/4fCwLLQy4CkhWHNCmhVhYQd/?format=pdf\&lang=pt.

Zucoloto, K. A. (2021). Ensino remoto durante a pandemia covid 19- o vírus como pedagogo. Brazilian Journal of Development, 7(5), 52048-52059. https://www.brazilianjournals.com/index.php/BRJD/article/view/30313/23841. 